\title{
Short-latency somatosensory evoked potentials (SSEPs) of the tibial nerves in spinal cord injuries
}

\author{
A Kovindha MD, R Mahachai MD \\ Rehabilitation Medicine Division, Faculty of Medicine, Chiang Mai University, Chiang \\ Mai 50002, Thailand.
}

Stimulations of the tibial nerves of 76 spinal cord injured patients revealed short-latency somatosensory evoked potentials (SSEPs) especially P37 recorded from the scalp. The SSEPs findings can be classified by degrees of impairment into 5 different types as follows:

Type 1: Absence of P37. This was found in all patients with complete cord lesions as well as patients with loss of joint sense.

Type 2: Decreased amplitude and prolonged latency. This was elicited in patients with moderate to severe central cord lesions.

Type 3: Prolonged latency only.

Type 4: Decreased amplitude only.

Type 5: Normal P37, which was mostly seen in patients with mild central cord lesion.

The study demonstrated that SSEPs of the tibial nerves are related to joint sense and seem to relate to the extent of cord damage, especially of central cord and complete cord lesions. It can be done as early as during the first week post injury, particularly in an uncooperative patient suspected of having spinal cord injury, in which case the clinical assessment may be difficult and unreliable.

Key words: short-latency somatosensory evoked potentials (SSEPs); spinal cord injury.

\section{Introduction}

After using computer averaging technique, cerebral response and somatosensory evoked potentials (SEPs) following electrical stimulation of peripheral nerve in man were first reported by Dawson. ${ }^{1}$ Thereafter, many studies of SEPs have been published concerning techniques, their origins and clinical uses.

Early study in patients with spinal cord injuries showed that no SEPs were elicited in complete cord lesion whilst in some patients with an incomplete lesion, such potentials were present. $^{2}$ Subsequently, others demonstrated the presence of SEPs in cases with a complete lesion,,$^{3,4}$ and concluded that there was a better prognosis of recovery. ${ }^{5,6}$ This was opposed by others. The presence of SEPs does not always predict recovery, it only permits quantitative evaluation of the somatosensory sys- tem, especially of joint sense. ${ }^{7,8}$ This was confirmed by the study in those with a Brown-Séquard lesion showing impairment of cortical SEPs after stimulation of the leg ipsilateral to the side of cord injury, ${ }^{9}$ and by animal studies showing that dorsal column, dorsolateral and dorsal spinocerebellar tracts are responsible for SSEPs; whereas the anterolateral (spinothalamic) tract affects later waves. ${ }^{10,11.12}$

This investigation was to study whether SSEPs would show any relation to different clinical cord lesions, and may give enough evidence regarding the integrity of the spinal cord after injury.

\section{Methods}

Neurological examination was performed on every spinal injured patient with a neurological deficit admitted to the Maharaj 
Nakorn Chiang Mai Hospital. Motor and sensory modalities were graded according to the severity of impairment (Table I). Then, clinical cord lesions were identified regarding neurological deficits (Table II).

Using a Neuromatic 2000C, SSEPs were recorded with bandpass filter set at $20-2000 \mathrm{~Hz}$. Constant current square-wave pulses of 200 microsecond duration at a rate of 3 per second were delivered by stimulating electrodes placed over the tibial nerve behind the medial malleolus. Current strength was determined for each subject until movements of the toes were seen or a maximum at $20 \mathrm{mAmp}$. Lumbar and scalp SEPs were recorded from the first lumbar spine referenced to the contralateral iliac crest and from $\mathrm{Cz}$ referenced to $\mathrm{Fz}$ (International $10-20$ system) respectively by using needle recording electrodes. This cephalic reference $(\mathrm{Fz})$ was chosen to minimise contamination by artifacts. ${ }^{13}$ Patients should be relaxed in the supine position to reduce myogenic potentials. ${ }^{14}$ At least 200 sweep repetitions were averaged for each trial and 2 replications were performed to identify the exact responses. Amplitude and latency of lumbar potential (LP) and SSEPs, ie. the first positive (downward) peak labelled $\mathrm{P} 3 \overline{7},{ }^{14}$ were then compared with the control data of our previous study ${ }^{15}$ as follows:

Mean predictive LP latency = $-5.939+0.155$ Height $(\mathrm{cm}) ; \mathrm{SE}=$ 0.981 .

Mean LP amplitude (baseline to peak) $=1.24$ microV; $S D=0.38$.

Mean predictive $\mathrm{P} 3 \overline{7}$ latency $=$ $-6.159+0.256$ Height $(\mathrm{cm}) ; \mathrm{SE}=$ 1.404 .

Mean P37 amplitude (baseline to peak $)=1.97$ microV; $\mathrm{SD}=0.83$.

The latency is prolonged if it is more than mean $+3 \mathrm{SE}$, while amplitude is decreased if it is less than mean - SD. Due to the correlation between latency and height, ${ }^{15}$ we compared the patients' data with the predictive values corrected by height as shown above.

Table I Grading of motor and sensory impairments below level of injury

\begin{tabular}{llll}
\hline Grade & Motor & Pinprick & Joint sense \\
\hline 0 & $\begin{array}{l}\text { loss } \\
\text { useless }\end{array}$ & $\begin{array}{l}\text { loss } \\
\text { diminished }\end{array}$ & $\begin{array}{l}\text { loss } \\
\text { appreciation of move- } \\
\text { ment } \\
\text { appreciation of move- } \\
\text { ment and direction, but } \\
2\end{array}$ \\
useful & normal & $\begin{array}{l}\text { less reliable } \\
\text { normal }\end{array}$ \\
\hline
\end{tabular}

Table II Clinical cord lesions according to neurological impairments

\begin{tabular}{|c|c|c|c|}
\hline \multirow[b]{2}{*}{ Lesions } & \multicolumn{3}{|c|}{ Degrees of neurological impairments } \\
\hline & Motor & Pinprick & Joint sense \\
\hline Complete cord transection & 0 & 0 & 0 \\
\hline Anterior cord & $0-1$ & $0-1$ & 3 \\
\hline \multicolumn{4}{|l|}{ Central cord } \\
\hline severe & 0 & $0-1$ & $0-2$ \\
\hline moderate & 1 & 1 & $1-2$ \\
\hline mild & 2 & $1-2$ & $1-3$ \\
\hline Posterior cord & 3 & 2 & $0-1$ \\
\hline \multicolumn{4}{|l|}{ Others } \\
\hline motor preserved only & $1-2$ & 0 & 0 \\
\hline unclassified & $1-2$ & 1 & 0 \\
\hline
\end{tabular}




\section{Results}

There were 100 patients in this study but only 76 spinal cord injured patients were included. The others were excluded due to abnormal or absence of LP suggesting conus medullaris or cauda equina lesions. Fortyseven patients were quadriplegic and 29 were paraplegic. There were 36 complete and 40 incomplete lesions. Average age was 36 years. Most patients were evaluated within the first month and only 8 cases were studied within the first week post injury.

According to SSEPs, there were 5 different types of tibial nerve $\mathrm{P} \overline{7}$ findings among these patients concerning the severity of impairment as follows (Fig 1):

Type 1: absence of P37.

Type 2: decreased amplitude and prolonged latency.

Type 3: prolonged latency only.

Type 4: decreased amplitude only.

Type 5: normal P37.

The relationships between $\mathrm{P} \overline{37}$ findings and joint sense as well as clinical cord lesions are shown in Table III and IV respectively.

Type 1 was found in all who had complete cord lesions (36 cases) as well as in patients with either total loss or moderate to severe impairment of joint sense.

Type 2 was mostly elicited in patients with moderate to severe impairment of joint sense, and in cases with moderate to severe central cord lesions.

In one patient with useful motor and diminished pinprick sensation but loss of joint sense, type 2 was detected. This was done on the eighth day post injury. On the other hand, there were 7 cases (13 responses) whose joint sense was preserved but impaired, where P37 could not be identified. In only 2 of these, the SEPs studies were done within the first week after injury. While 6 out of 8 cases retaining joint sense were also examined during the first week, P37 was still preserved.

Type 3 was seen in patients with mild to moderate impairment of joint sense, and

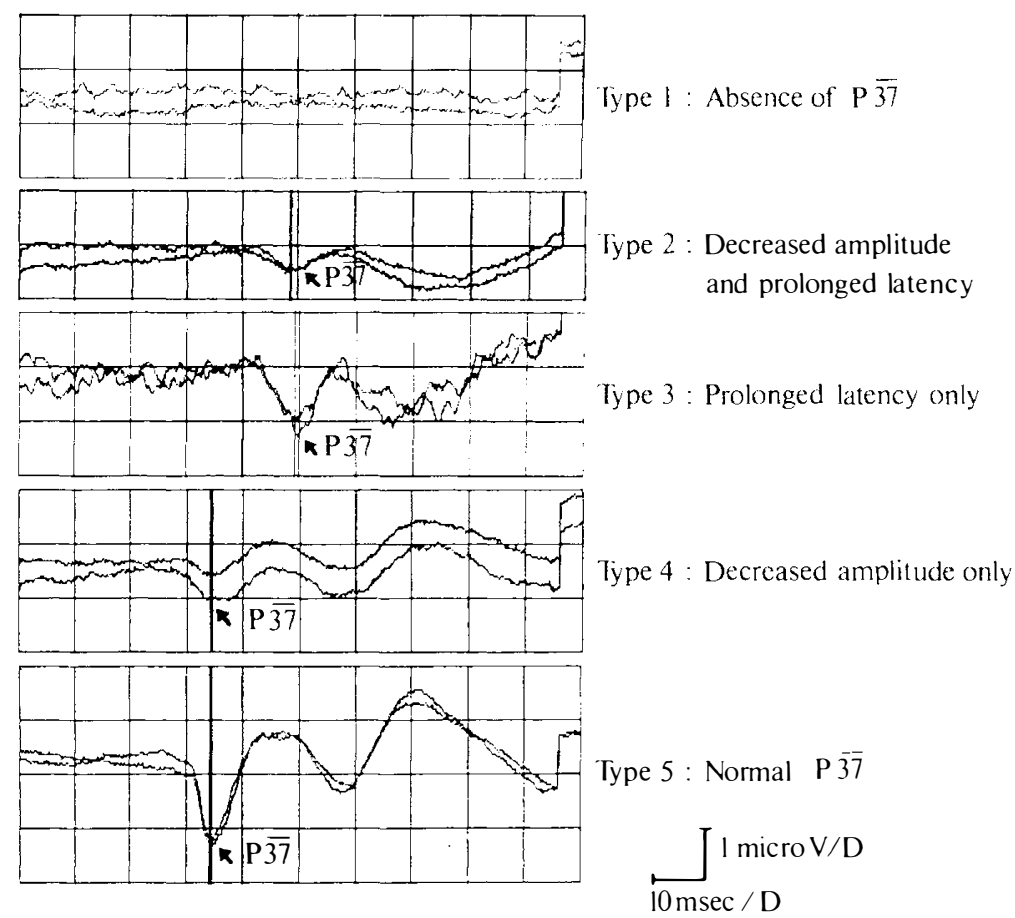

Figure 1 Five different types of $\mathrm{P} \overline{3}$ findings in spinal cord injuries. Each pair of traces depict repetition of evoked responses from the same side. 
Table III The relation between joint sense and SSEPs (P37) findings

\begin{tabular}{lrrrrr}
\hline Joint sense & \multicolumn{5}{c}{ No. of responses } \\
Grade & Types of $\mathrm{P} \overline{37}$ & 1 & 2 & 3 & 4 \\
\hline 0 & 80 & 1 & & & 5 \\
1 & 11 & 13 & 1 & 4 & 3 \\
2 & 2 & 2 & 3 & 1 & 3 \\
3 & & 2 & & 7 & 19 \\
\hline
\end{tabular}

There were 2 responses for each patient and a total number of 152 responses were evaluated.

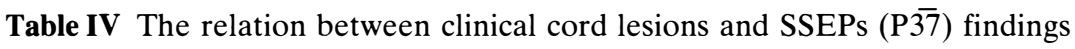

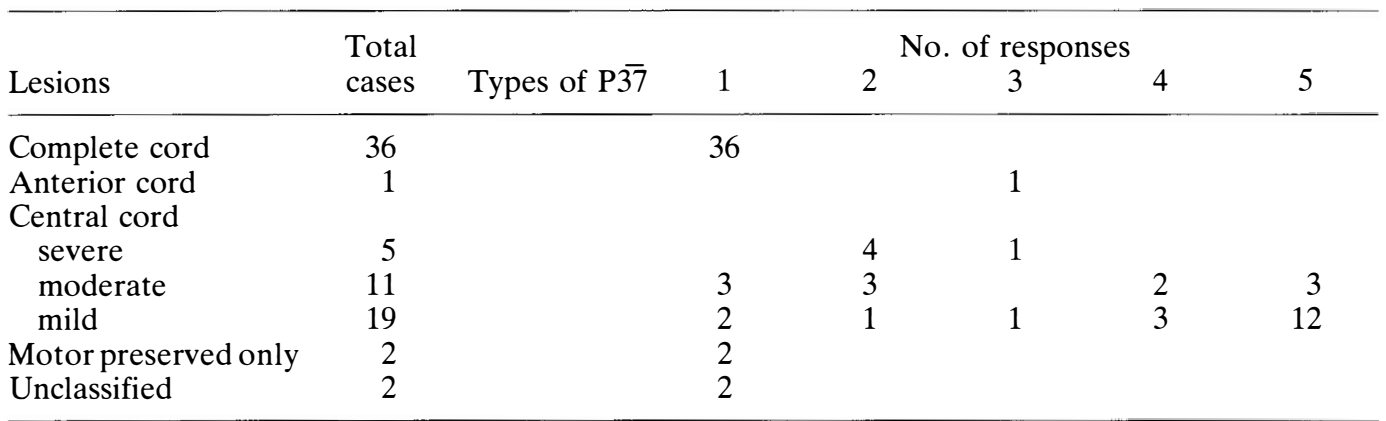

Numbers in this table indicate the summation of the best responses between the two sides of P $\overline{37}$ findings in each case.

types 4 and 5 were usually elicited in cases of mild central cord lesions or in patients with normal to mild impaired joint sense.

\section{Discussion}

The results of this study showed that SSEPs are related to joint sense and also confirmed that the less the degree of joint sense impairment is, the more likely will the P $\overline{37}$ findings tend to be normal (from type 1 to 5). In mild degree impairment, either amplitude or latency of P $\overline{37}$ is affected, while with severe impairment both parameters are usually affected.

This study advocated that the dorsal spinocerebellar tract carrying impulses from receptors in the joints and muscles was responsible for 'joint sense' of the lower or hind limb, ${ }^{16}$ and is the main pathway of propagation of the evoked responses. ${ }^{12}$

Regarding those with a complete cord lesion, many studies have advocated its relation to the loss of SSEPs, ${ }^{2,8}$ while others reported the presence of SSEPs in some cases with a clinical lesion. ${ }^{4}$ In this study, no patients with complete cord lesion with preservation of P $\overline{37}$ were found. It indicates that if SSEPs are absent, either a complete or a severe central cord lesion with severe impairment of joint sense should be considered. The presence of SSEPs reflect an incomplete lesion. However, the type of SSEPs findings may help in predicting the degree of joint sense impairment and the severity of the clinical cord lesion, especially the extent of central cord damage and complete cord transection.

The time at which the test (SEPs) was done did not seem to affect the evoked responses. Although some patients, those with preserved joint sense, were examined within the first week after injury, SSEPs were still elicited. Oedema at the site of injury did not alter the result, as reported previously. ${ }^{17}$ However, if there is clinical improvement regarding joint sense, the SSEPs will improve in latency and/or amplitude. Because of the rarity of posterior cord lesion, the persistence of absence of 
SSEPs may be used to predict complete cord lesion or severe cord damage.

Although this investigation did not study long-latency SEPs which were said to propagate via the anterolateral tract in animal studies, ${ }^{10,11,12}$ there was one case with loss of joint sense but preserved pinprick sensation, showing abnormal low amplitude and prolonged latency of P $\overline{37}$. However, we could not conclude that the spinothalamic tract was responsible for this finding.

To date, the study of SSEPs is an adjunctive procedure in the evaluation of joint sense and of the integrity of the spinal cord in those whose clinical assessment may be difficult and unreliable. It can be performed with expected accurate results as early as in the first week after injury and can be repeated later to confirm a definite interpretation. The presence or the improvement of SSEPs findings do not ensure a good prognosis of functional recovery because SSEPs only represent an intact sensory pathway in the spinal cord. However, the degree of SSEPs impairment also seems to relate to the severity of a central cord lesion.

\section{References}

1 Dawson GD (1947) Cerebral responses to electrical stimulation of peripheral nerve in man. J Neurol Neurosurg Psychiatry 10: 134-40.

2 Perot PL Jr (1973) The clinical use of SEPs in spinal cord injury. Clin Neurosurg 20: 367-81.

3 York DH, Watts C, Raffensberger M, Spagnolia T, Joyce C (1983) Utilization of somatosensory evoked potentials in spinal cord injury: prognostic limitation. Spine 8(8): 832-9.

4 lob I, Salar G, Mingrino S, Pellegrini A, Ori C (1984) Indications and limits of somesthetic evoked potentials in spinal cord trauma. J Neurosurg Sci 28: 191-3.

5 Rowed DW, McLean JAG, Tator CH (1978) Somatosensory evoked potentials in acute spinal cord injury: prognostic value. Surg Neurol 9: 203-10.

6 Perot PL Jr, Vera CL (1982) Scalp-recorded SEPs to stimulation of nerves in the lower extremities and evaluation of patients with spinal cord trauma. Ann NY Acad Sci 388: 359-68.

7 Dorfman LJ, Perkash I, Bosley TM, Cummins KL (1980) Use of cerebral evoked potentials to evaluate spinal somatosensory function in patients with traumatic and surgical myelopathies. J Neurosurg 52: 654-60.

8 Chabot R, York DH, Watts C, Waugh WA (1985) Somatosensory evoked potentials evaluated in normal subjects and spinal-injured patients. J Neurosurg 63: 544-51.

9 Bloom KK, Goldberg G (1989) Tibial nerve somatosensory evoked potentials in spinal cord hemisection. Am J Phys Med Rehabil 68(2): 59-65.

10 Katz S, Martin HF, Blackburn JG (1978) The effects of interaction between large and small diameter fiber systems on the SEP. Electroenceph Clin Neurophysiol 45: 45-52.

11 Martin HF, Katz S, Blackburn JG (1980) Effects of spinal lesion on somatic evoked potentials affected by interactions between afferent inputs. Electroenceph Clin Neurophysiol 50: 186-95.

12 Powers SK, Bolger CA, Edwards MSB (1982) Spinal cord pathways mediating somatosensory evoked potentials. J Neurosurg 57: 472-82.

13 Cracco RQ (1980) Scalp-recorded potentials evoked by median nerve stimulation: subcortical potentials, travelling waves and somatomotor potentials. In: Desmedt JE, editor. Clinical Uses of Cerebral, Brainstem and Spinal Somatosensory Evoked Potentials. Kargel, New York: 1-26.

14 AAEE glossary of terms in clinical electromyography (1987) Muscle Nerve 10 (Suppl 8): G 1-60.

15 Wisoodthimark T, Kovindha A, Yenjit C (1990) Posterior tibial nerve somatosensory evoked potentials (SEPs) in patients with lumbar disc herniation. Chiang Mai Med Bull 29: 113-22.

16 Brodal P, Eric R (1981) The somatic afferent pathways. In: Brodal A, editor. Neurological Anatomy: In Relation to Clinical Medicine. 3rd ed. Oxford University Press, Oxford: 46-147.

17 Lozes G, Cama A, Lesoin F et al (1985) Interet diagnostique et prognostigue de L'electromyographie diaphragmatique et des potentiels evoques somesthésiques dans las traumatismes vertebro-medullaires cervicaux. Neurochirurgie 31: 449-59. 